\title{
Base Isolated 4-Story Hospital Building "Vanadzor" - Part 2 - Details on Construction of this Unique Building
}

\author{
Mikayel Melkumyan* \\ President of the Armenian Association for Earthquake Engineering, Director of the "Melkumyan Seismic \\ Technologies" LLC
}

*Corresponding Author: Mikayel Melkumyan, President of the Armenian Association for Earthquake Engineering, Director of the "Melkumyan Seismic Technologies" LLC

\begin{abstract}
In 2015 the author has published a paper "Structural Concept and Analysis of the 4-story Base Isolated Hospital Building "Vanadzor". This work described the approaches developed by the author in design of overall bearing structure of the building and its base isolation system, mentioning the complicated architectural solution in plan and along the height of this building. Information on design and analysis of base isolated hospital building "Vanadzor" provided in already published paper confirms the fact that due to created structural concept of the whole building and its base isolation system a unique and unprecedented structure was constructed in the city of Vanadzor, the third biggest city of Armenia. That is why this paper has drawn the interest of many researchers and designers. By the way, starting from 2015, the year of publication of the paper about this hospital building, more than 2000 researchers and engineers across the world have got acquainted with it through different well-known scientific networks (particularly Research Gate, Mendeley, etc.). Therefore, they approached the author through these scientific networks with the request to provide more information also on the details of construction of this unique building. To satisfy these multiple queries the below paper was prepared which presents and describes some stages of construction of the Hospital Building "Vanadzor".
\end{abstract}

Keywords: Base Isolation, Hospital Building, Reinforced Concrete Structures, Horizontal Stiffness, Location of Isolators by Clusters, Horizontal Displacement, Construction Details, Unique Structural Solutions

\section{INTRODUCTION}

One of the recent projects financed by the government of Armenia (Healthcare Project Implementation Unit, Ministry of Health, the World Bank credit) on analysis and design of 4-story base isolated hospital building "Vanadzor" (Fig. 1) was accomplished in 2013. Construction of this building in the city of Vanadzor was finished in 2016.

Considered building in its plan and along its height has complicated architectural solution, which was developed in Armproject OJSC. Therefore, the author of this book was approached with the request to design the base isolation system for this building to simplify its overall structural solution. The matter is that dimensions of this building in plan are about $80 \times 80 \mathrm{~m}$ and, according to the Armenian Seismic Code, only application of base isolation will allow to avoid dividing the building into several parts separated by the anti-seismic vertical gaps between them. This is another unique feature of seismic isolation. Otherwise, at least four anti-seismic vertical gaps would be needed to design this structure in conventional way.

Isolation system of this building is designed at the level of the basement floor [1]. There are strong and rigid reinforced concrete $(\mathrm{R} / \mathrm{C})$ structural elements designed within the limits of the basement. The cross section of the foundation strips is $\mathrm{T}$ - shaped with the area of its bottom flange equal to $1400 \times 400(\mathrm{~h})$ $\mathrm{mm}$ and of its web $-800 \times 700$ (h) $\mathrm{mm}$. The cross section of most of the columns is also T - shaped so that the area of its flange is equal to $1800 \times 600 \mathrm{~mm}$ and of its web $-900 \times 600 \mathrm{~mm}$. Some of the columns are designed with the $\mathrm{L}$ - shaped cross section. Consequently, the central core of all columns has a cross section equal to $600 \times 600 \mathrm{~mm}$. The height of the columns is equal to $2850 \mathrm{~mm}$ and the seismic isolators are installed just on top of them. The cross section of beams above the seismic isolators is equal to $600 \times 650$ (h) mm (Fig. 2). 


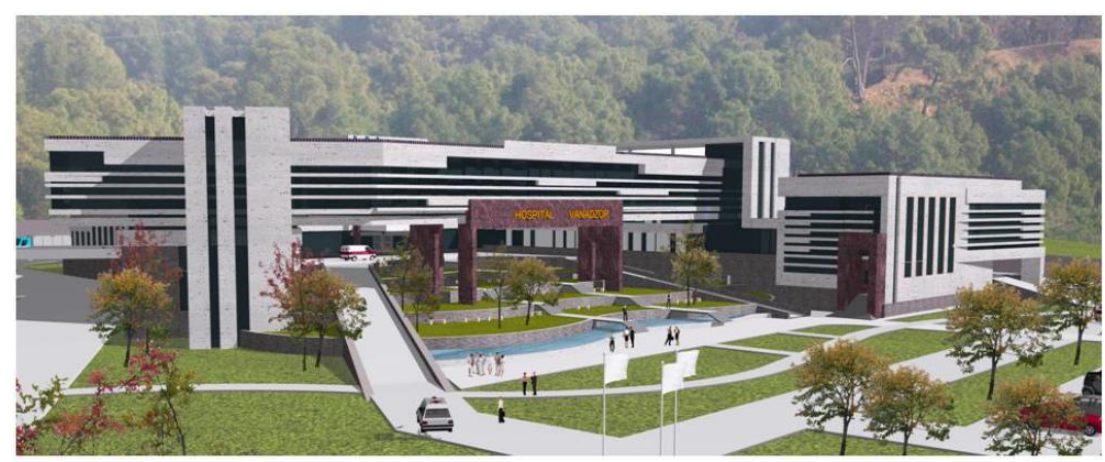

Figure1. Design view of the 4 - story base isolated hospital building "Vanadzor"

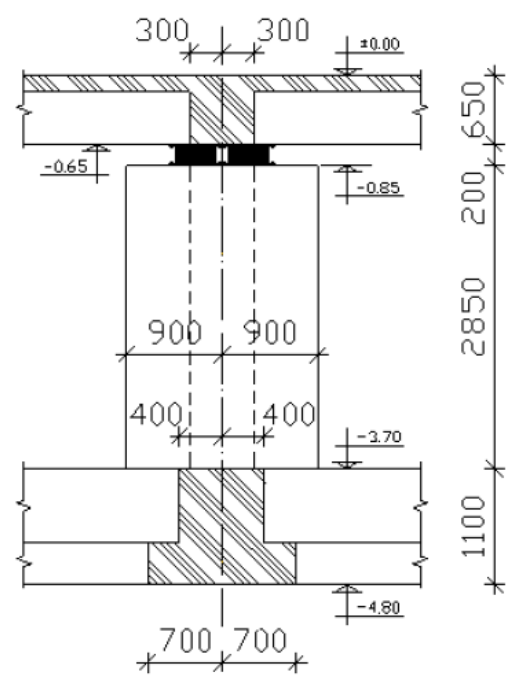

Figure2. Geometrical dimensions of the foundation strips, T-shaped columns of the basement, and the upper beams above the seismic isolators of the 4 - story base isolated hospital building "Vanadzor"

The shear walls are designed with the thickness equal to $300 \mathrm{~mm}$ and they are located along all the exterior axes of the basement. Some of the shear walls are solid and others have door or window openings. The accepted structural solution allowed obtaining a rigid system below the isolation plane. This provides a good basis for effective and reliable behavior of isolators during the seismic impacts. Of course, the superstructure (the part of building above the isolation plane, which consists of 3 floors) should have substantial rigidity for the same purpose. This was achieved by using $\mathrm{R} / \mathrm{C}$ columns with cross section of $400 \times 400 \mathrm{~mm}$ and $200 \mathrm{~mm}$ thick shear walls around the staircases and elevators' shafts. The thickness of R/C slabs was set at $150 \mathrm{~mm}$ for all floors. In the considered building the approach suggested in $[2,3,4]$ on installation of the clusters of small rubber bearings instead of a single large bearing between the basement columns and the upper beams of the seismic isolation system was used. Corresponding examples of installed isolators are shown in Figure 3.
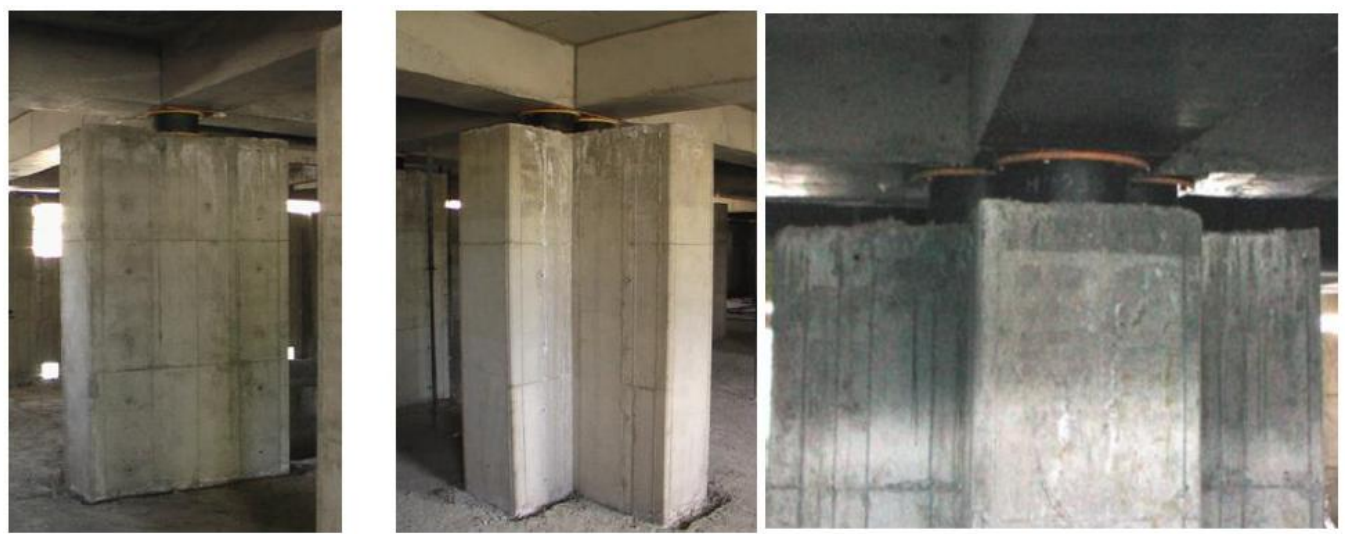

Figure3. Examples on installation of rubber bearings' clusters in the 4 - story base isolated hospital building "Vanadzor" during construction 
Thus, different numbers of rubber bearings are installed in different locations at the level of basement floor. However, all rubber bearings in this building are of the same size (diameter $380 \mathrm{~mm}$, height 202 $\mathrm{mm}$ ) and characteristics. They have horizontal stiffness equal to $0.81 \mathrm{kN} / \mathrm{mm}$, a damping factor of about $13-15 \%$, can develop horizontal displacement of up to $280 \mathrm{~mm}$ (about $220 \%$ of shear strain), and can carry a vertical design load of up to $1500 \mathrm{kN}$. They are made from neoprene and were designed and tested locally $[5,6]$.

The approach on installation of the cluster of small rubber bearings instead of a single large bearing is not a typical one for the buildings with isolation systems. The advantages of this approach are the following: increased seismic stability of the building; more uniform distribution of the vertical dead and life loads as well as additional vertical seismic loads on the rubber bearings; small bearings can be installed by hand without using any mechanisms; easy replacement of small bearings, if necessary, without using any expensive equipment; easy casting of concrete under the steel plates with anchors and recess rings of small diameter for installation of bearings; neutralization of rotation of buildings by manipulation of the number and location of bearings in the seismic isolation plane, etc. [7, 8]. One more advantage was pointed out by Prof. Kelly during the 11th World Conference on Seismic Isolation in Guangzhou, China. Positively evaluating the suggested approach he mentioned that in the course of decades the stiffness of neoprene bearings may increase, and in order to keep the initial dynamic properties of the isolated buildings the needed number of rubber bearings can be dismantled from the relevant clusters [9]. Thus, thanks to the suggested approach, more rational solution can be achieved, which is increasing the effectiveness of isolation system in general.

From the above given description of the hospital building "Vanadzor" and from Figure 1 it can be noticed that the front of the building has a unique structural solution. In this part design envisages construction of only fourth floor which connects like a bridge the left and right wings of the building. Within the limits of its span this so called "bridge" is supported by four hollow columns with outside dimensions equal to $2600 \times 2600 \mathrm{~mm}$ and inside dimensions $-1800 \times 1800 \mathrm{~mm}$. Under each of such columns ten seismic isolation rubber bearings are installed (Fig. 4).
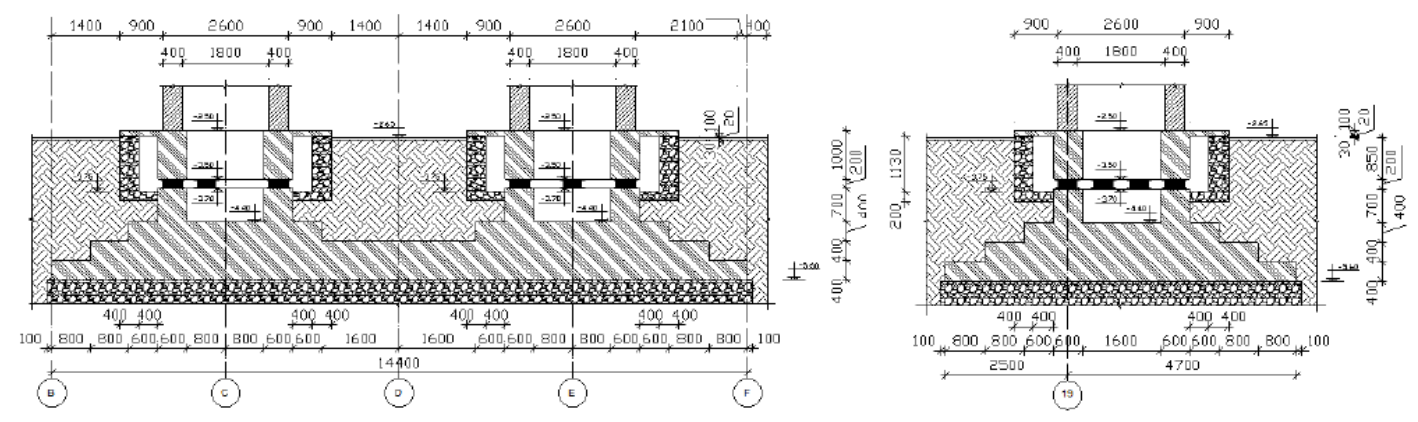

Figure4. Longitudinal and transverse vertical elevations of the hollow columns at the level of foundation showing location of the seismic isolation rubber bearings under these columns in the 4-story base isolated hospital building "Vanadzor"

\section{Illustration of Some Stages of Construction of the 4-Story Base Isolated HOSPITAL BUILDING "VANADZOR"}

Above given information on the base isolated hospital building "Vanadzor" confirms the fact that due to created structural concept of the whole building and its base isolation system a unique and unprecedented structure was constructed in Armenia.

Control over the construction of this unique structure was carried out directly by the author of this paper who was also the author of the developed design of seismic isolation system. Below given pictures in Figures 5 and 6 are illustrating construction of the hospital building basement's columns which have Tshaped or L-shaped cross sections and the isolators' lower sockets on top of them anchored in the bodies of columns.

Usually, in many other buildings designed by the author $[10,11,12]$ the columns located immediately below the seismic isolators are connected to each other by beams creating a frame structure with no slab at this level. At such structural solutions, the columns have typically square cross-section with dimensions of $500 \times 500 \mathrm{~mm}, 600 \times 600 \mathrm{~mm}$ or $700 \times 700 \mathrm{~mm}$. In the given case of hospital building 
Base Isolated 4-Story Hospital Building "Vanadzor" - Part 2 - Details on Construction of this Unique Building

architects preferred to have columns without connecting beams. That is why the author suggested to design columns which have T-shaped or L-shaped cross sections, as this will provide the needed horizontal stiffness for the basement floor and its reliable behavior during the seismic impacts.

As mentioned above there are four hollow columns designed to support the fourth floor (bridge) at the front part (entrance) of the hospital building. At the same time, a single foundation is designed for every pair of columns (see Fig. 4). The constructed foundation with the isolators' lower sockets on top of them is shown in Figure 7. It should be emphasized that during the construction of these foundations, as well as the basement's columns, special attention was paid to ensuring that the lower sockets of seismic isolators were in a strictly horizontal position.

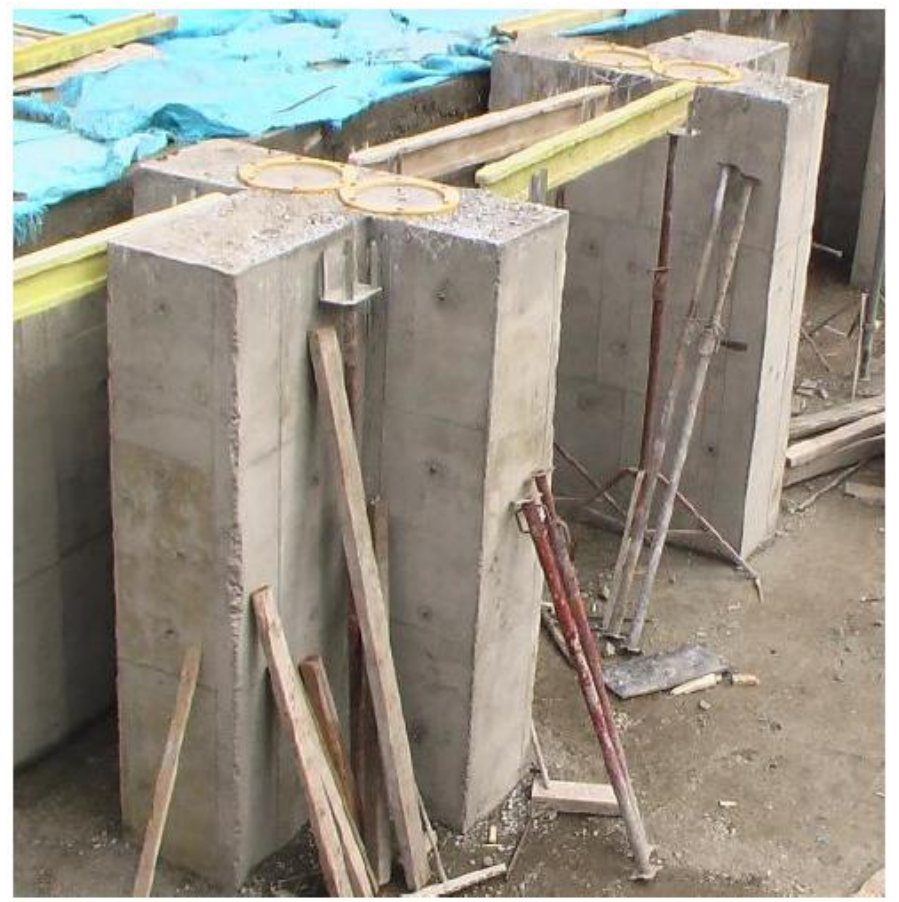

Figure5. Columns with the T-shaped cross section constructed in the basement with two seismic isolators' lower sockets on top of them

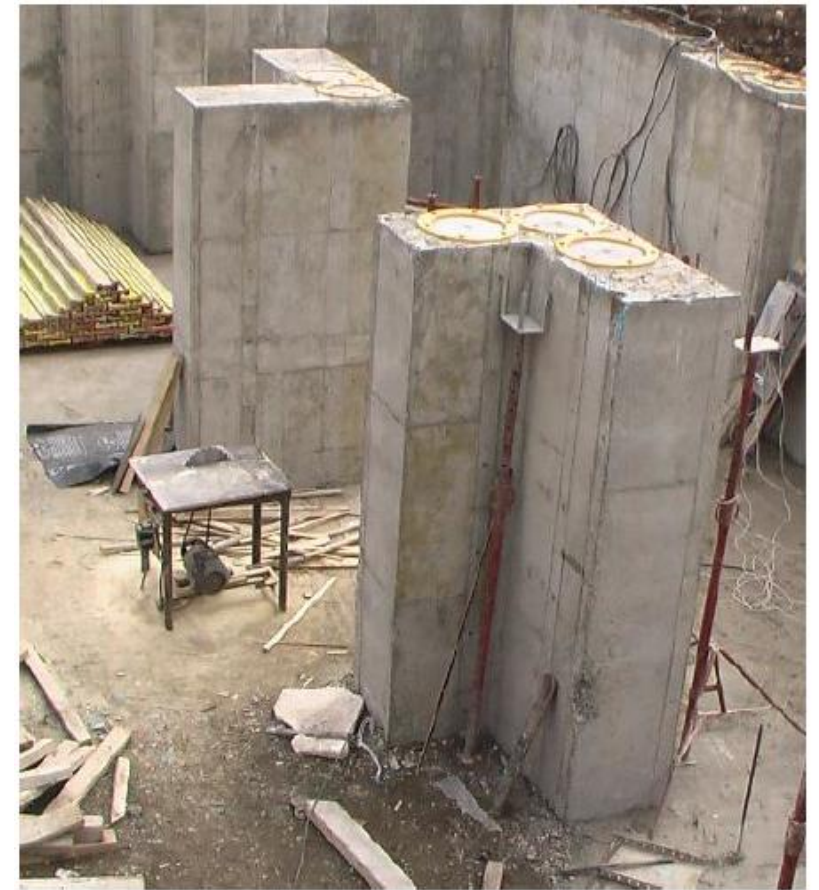

Figure6. Columns with the L-shaped cross section constructed in the basement with two or three seismic isolators' lower sockets on top of them 


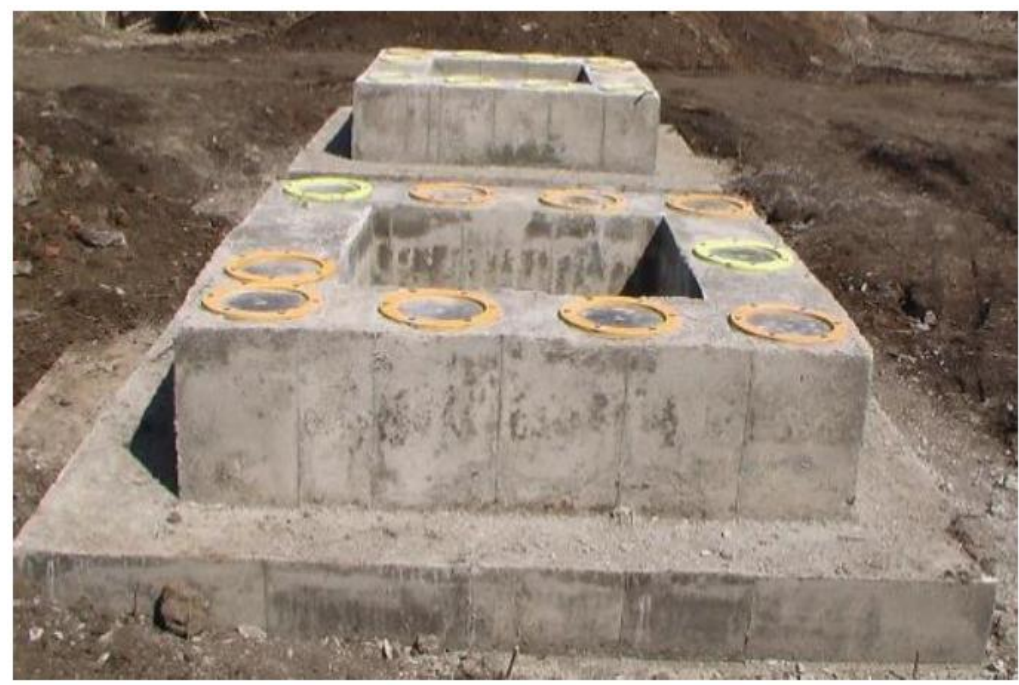

Figure7. View of the constructed foundation under the hollow columns to support the so called "bridge". Ten seismic isolators' lower sockets are placed on each foundation of the four hollow columns

When all the structural elements of the basement and of foundations under the hollow columns were finished, and the seismic isolation laminated rubber-steel bearings were installed in the lower sockets, then the works on construction of the superstructure start. First, upper sockets must be installed on all the seismic isolators (Fig. 8) and then construction of the upper beams above the isolators starts (Fig. 9).

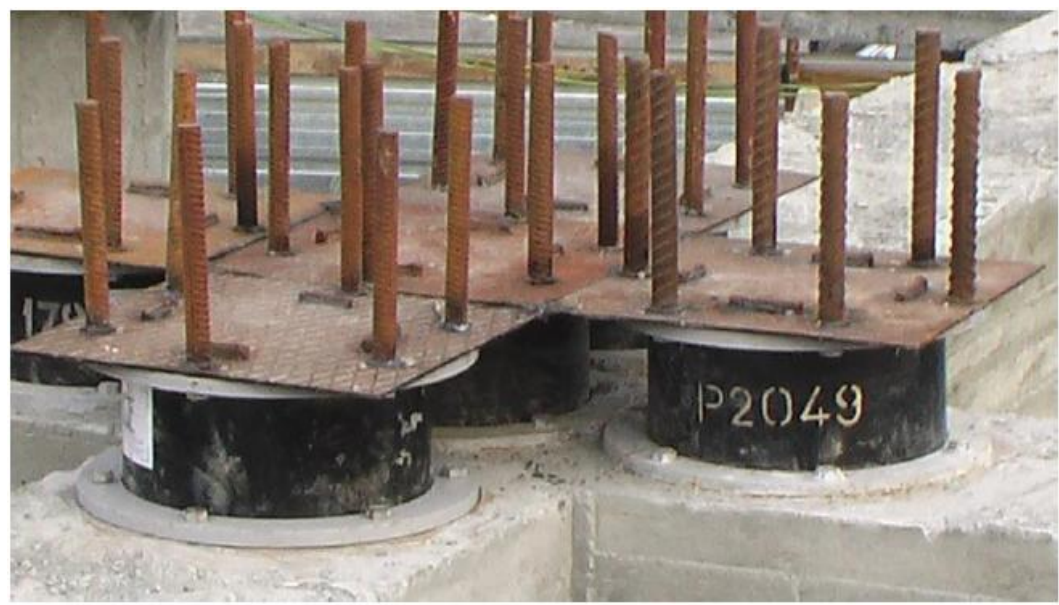

Figure8. View of the upper sockets with anchor rods installed above the seismic isolators

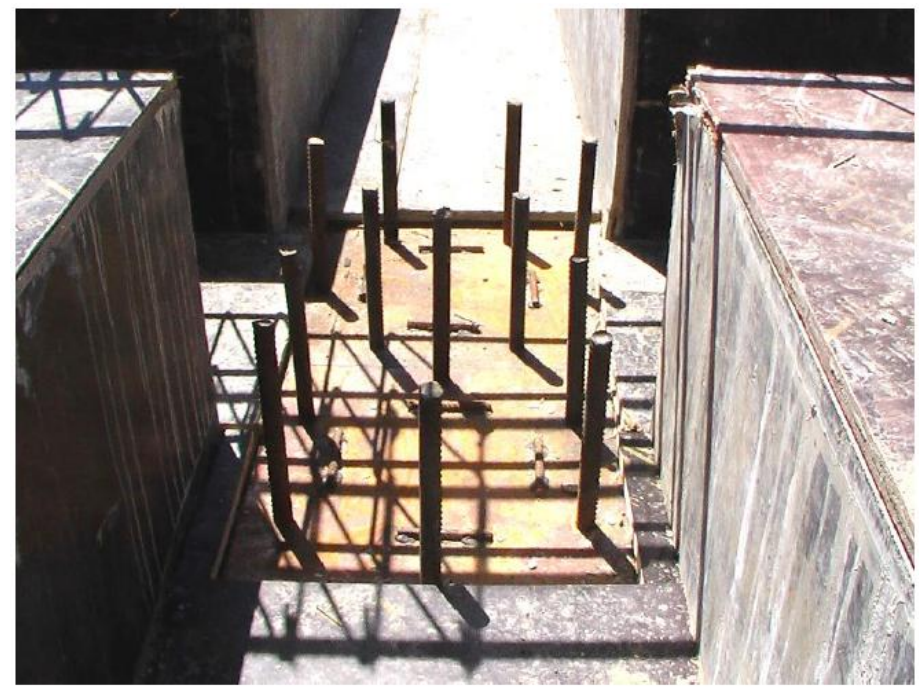

Figure9. View of the wooden forms of upper beams to be constructed immediately above the seismic isolators. Anchor rods of upper sockets will be anchored in the upper beams 
In parallel with this the similar operations must be done for the seismic isolation system designed under the four hollow columns of the central entrance. Figure 10 shows some stages of construction of these structural elements. From these pictures and from Figure 4 one can see that at the lower parts of the hollow columns the cantilever slabs are envisaged. The same type of the slabs is also envisaged along some parts of the perimeter of building where the level of the seismic isolation system in the basement is lower comparing to the outside ground level. In such places the trenches are dug and retaining walls are built forming the gap to create the possibility for free horizontal displacement of seismic isolation system. The gaps along some parts of the building and around the hollow columns are covered by cantilever slabs to protect the gaps from precipitations and to avoid possible accumulation of trash. However, the main purpose of this gap is to ensure unhindered movement of the superstructure, as well as effective action of the seismic isolation system and accommodation of its horizontal displacement during any seismic impact. The ground level at the main entrance around the hollow columns will further be increased so that the level of asphalt in this area will be $30 \mathrm{~mm}$ lower of the height of retaining walls.

a.

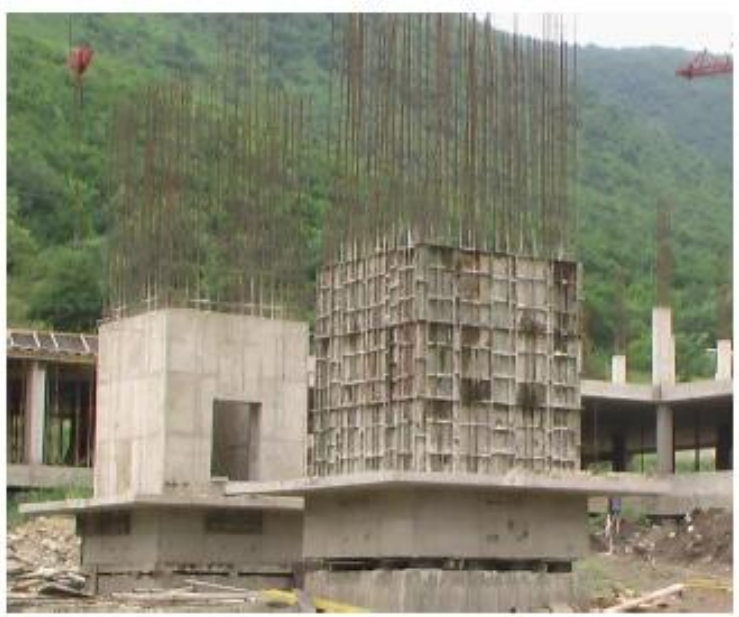

c.

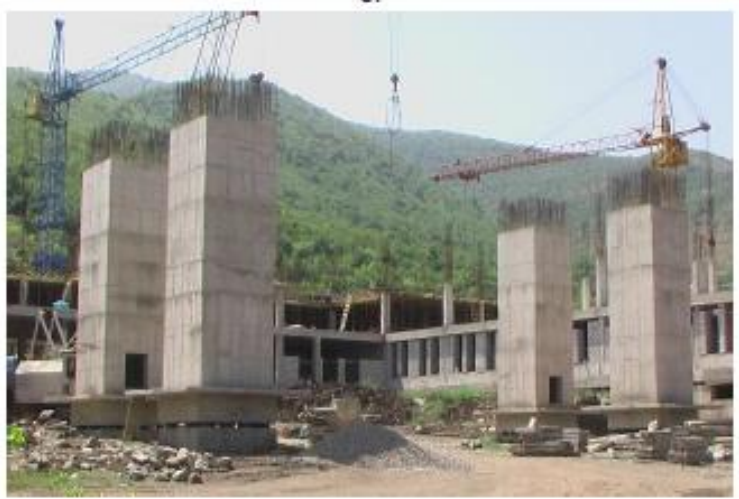

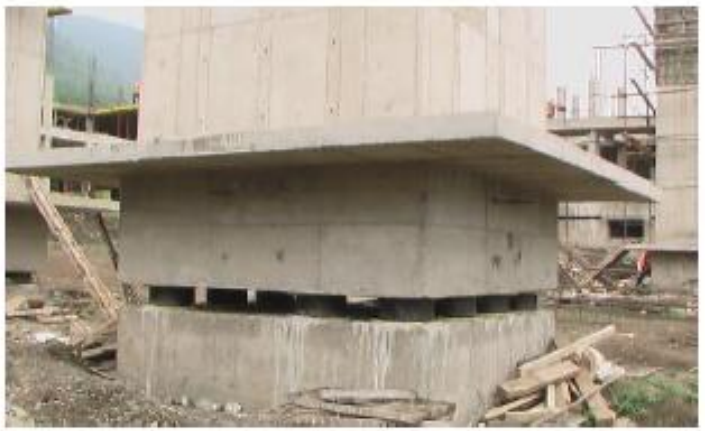

d.

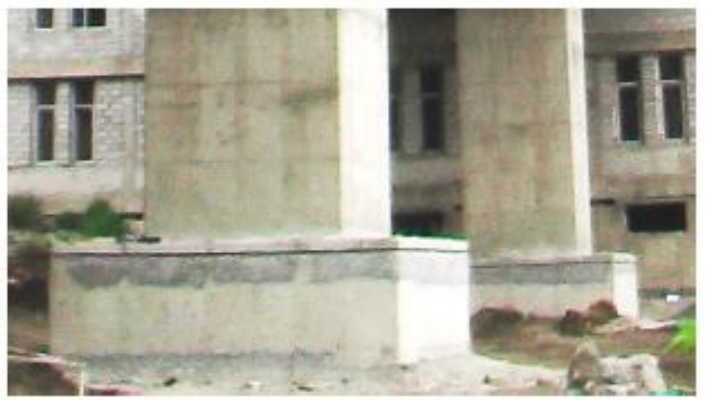

Figure10. Process of construction of the hollow columns above the seismic isolation plane (a), view of the lower part of already constructed hollow column with cantilever slab around it (b), view of constructed four hollow columns ready to support the fourth floor ("bridge") of the superstructure (c), and view of the retaining walls constructed around the hollow columns to form the seismic isolation gap (d)

The hollow columns ape rigid structural elements. To provide effective behavior of seismic isolation system these columns must have also sufficiently rigid connection with the beams of the fourth floor. These beams are clearly visible in the structures of the fourth floor - the "bridge" - shown by different pictures in Figure 11. Also, Figure 11 is illustrating construction of the most unique part of the hospital building "Vanadzor". To make this possible a special steel structure was designed and constructed for carrying the weight of the "bridge" during the process of casting the concrete in the wooden forms of its structural elements. This steel structure in the form of a braced frame was constructed from the ground and up to the bottom part of the "bridge" (the upper part of the hollow columns). Of course, after finishing of all the operations on construction of the fourth floor, and after the concrete of this floor received its design strength, the braced frame structure was dismantled. 

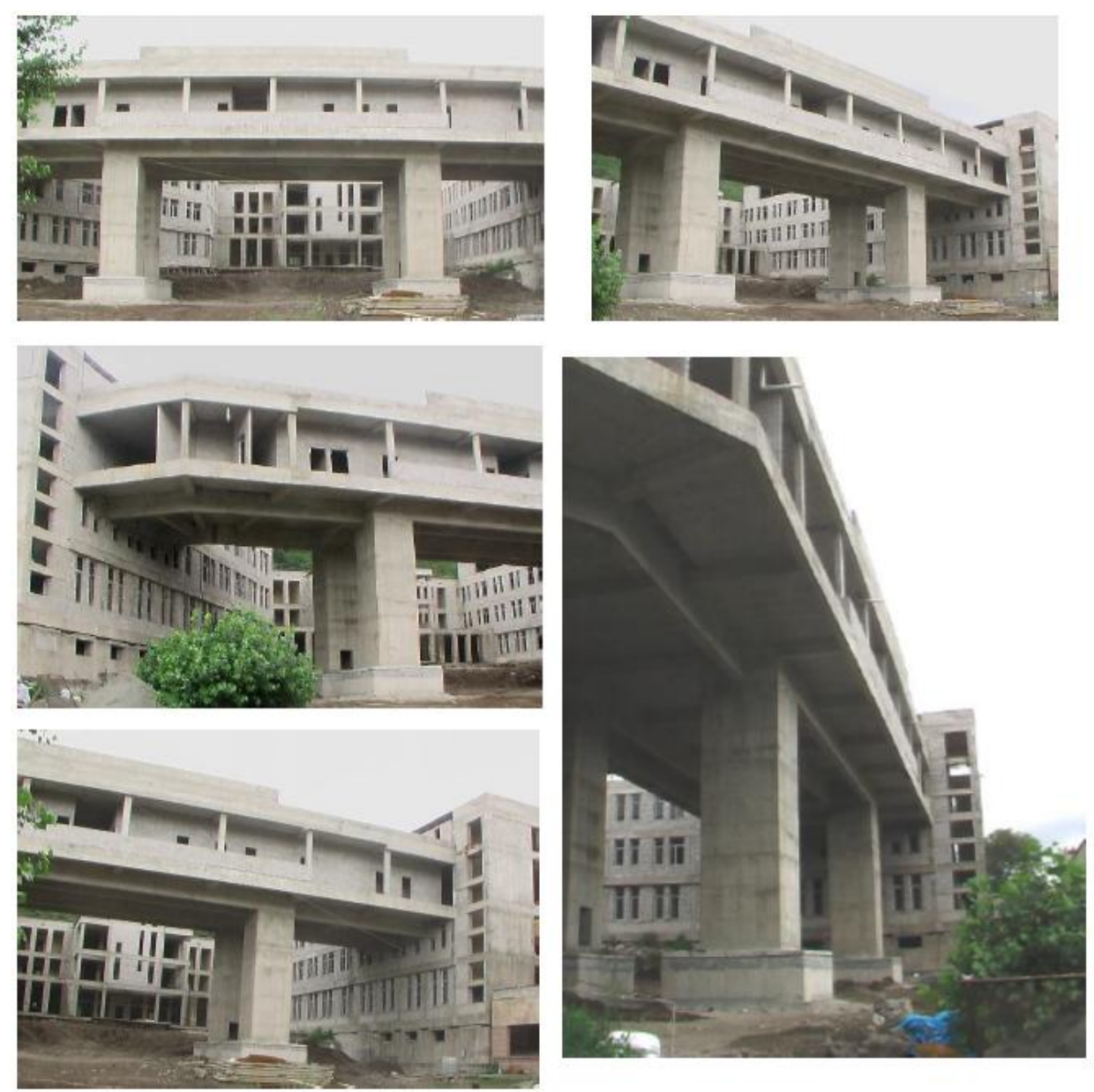

Figure11. The views of the four hollow columns supporting the fourth floor ("bridge") of the superstructure connecting the left and right wings of base isolated hospital building

Special attention needs to be paid also to the four staircases leading to the basement of the building. These are the double-flight stairs which have their own supports permitting to separate them from each other, thus, providing the gaps between the stairs and superstructure. Some examples of such gaps are show in Figure 12. Again, the purpose of these gaps is to ensure unhindered movement of superstructure supported by the seismic isolation system providing free development of its horizontal deformations.

In the basement floor limits, the elevator shafts have metallic carcasses, which are hung on new beams designed at the level of the upper beams of seismic isolation system. There are $100 \mathrm{~mm}$ gaps between the lower parts of the mentioned metallic shafts and bottoms of the elevator pits. The sizes of pits are chosen in such way that during design level earthquakes they allow free movement of elevator shafts, without touching the pit walls.
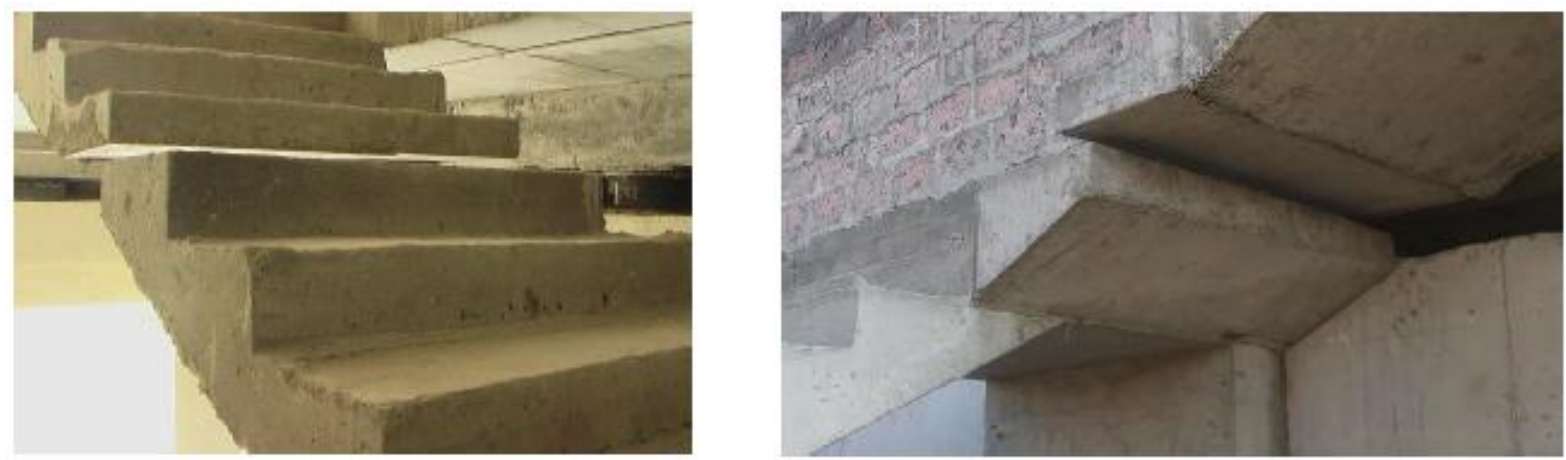

Figure12. Examples of gaps in stairs ensuring unhindered movement of superstructure

Final view of the recently constructed unique base isolated hospital building "Vanadzor" is shown in Figure 13. 


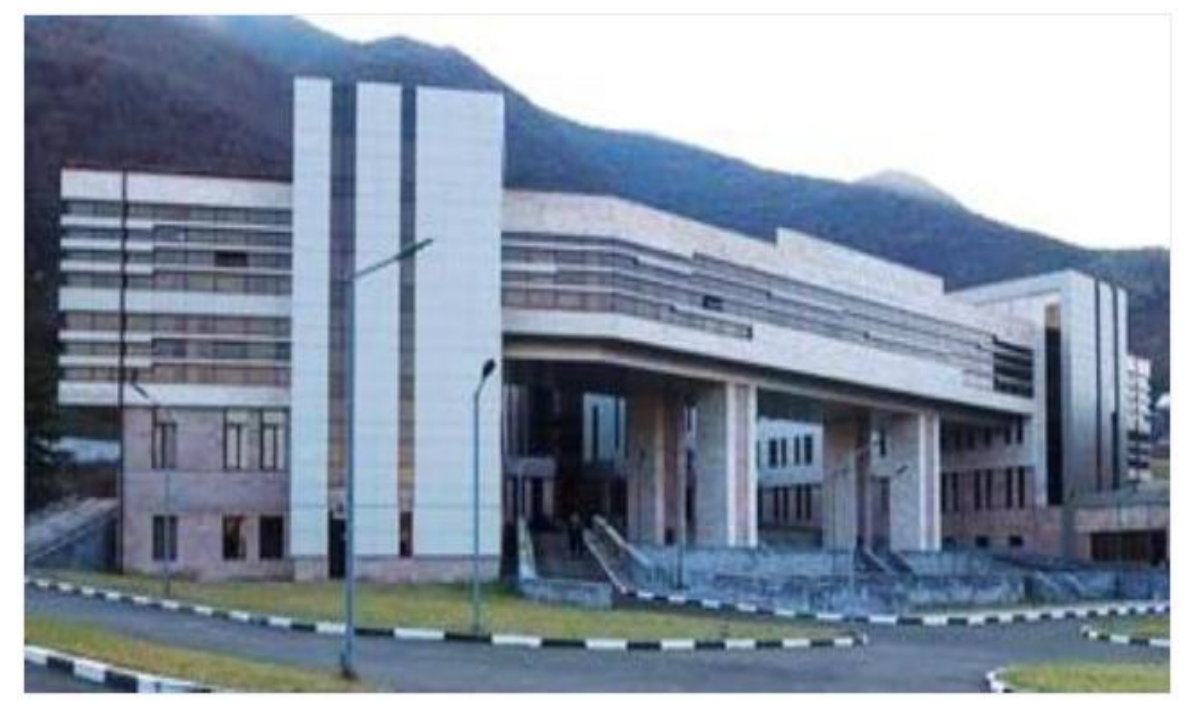

Figure13. View of the 4-story base isolated hospital building "Vanadzor" after completion of construction

\section{CONCLUSION}

This paper was written to satisfy the multiple queries from the scientists, structural and construction engineers, designers to describe some construction details of the base isolated hospital building "Vanadzor". Such a great interest among the mentioned specialists arouse regarding this unique building after the author has published a paper in 2015 "Structural Concept and Analysis of the 4-story Base Isolated Hospital Building "Vanadzor". More than 2000 researchers and engineers across the world have got acquainted with this paper through different well-known scientific networks (particularly Research Gate, Mendeley, etc.).

The given paper presents and describes some details and stages of construction of the mentioned unprecedented structure. Information is given on structural concept of the building and its seismic isolation system. The types of constructed columns (T- and L-shaped) with different number of seismic isolators on top of them are shown and solutions that lead to creation of the necessary rigidity of bearing structures below and above the seismic isolation system are explained. Details of fixation of seismic isolators in lower und upper sockets provided with the anchor rods to be structurally connected with the basement columns and the upper beams are illustrated. Construction of the most unique front part of the hospital building that includes four hollow columns supporting the fourth floor ("bridge") which in its turn connects the left and right wings of the building is described in detail.

\section{REFERENCES}

[1] Melkumyan M. (2015). Structural Concept and Analysis of the 4-story Base Isolated Hospital Building "Vanadzor". American Journal of Environmental Engineering and Science (AJEES), Vol.2, No.5: pp.44-52.

[2] Melkumyan M. and Hovhannisyan H. (2006). New approaches in analysis and design of base isolated multistory multifunctional buildings. Proceedings 1st European Conference on Earthquake Engineering and Seismology (a joint event of the 13th ECEE \& 30th General Assembly of the ESC), Geneva, Switzerland, Paper 194.

[3] Melkumyan M. (2007). Seismic isolation of civil structures in Armenia - development and application of innovative structural concepts. Proceedings ECCOMAS Thematic Conference on Computational Methods in Structural Dynamics and Earthquake Engineering, Rethymno, Crete, Greece, Paper 1691.

[4] Melkumyan M. (2009). Armenian seismic isolation technologies for civil structures - example on application of innovative structural concepts, R\&D and design rules for developing countries. Proceedings 11 th World Conference on Seismic Isolation, Energy Dissipation and Active Vibration Control of Structures, Guangzhou, China, Paper K01.

[5] Melkumyan M. (2001). The state of the art in development of testing facilities and execution of tests on isolation and bridge bearings in Armenia. Proceedings 5th World Congress on Joints, Bearings and Seismic Systems for Concrete Structures, Rome, Italy, Paper 044.

[6] Melkumyan M. and Hakobyan A. (2005). Testing of seismic isolation rubber bearings for different structures in Armenia. Proceedings 9th World Seminar on Seismic Isolation, Energy Dissipation and Active Vibration Control of Structures, Kobe, Japan, Vol. 2: pp. 439 - 446. 
Base Isolated 4-Story Hospital Building "Vanadzor" - Part 2 - Details on Construction of this Unique Building

[7] Foti D. and Mongelli M. (2011). Isolatori sismici per edifice esistenti e di nuova costruzione, Dario Flaccovio Editore, (in Italian).

[8] Melkumyan M. (2011). New solutions in seismic isolation. "LUSABATS", Yerevan.

[9] Melkumyan M. (2014). Seismic isolation retrofitting experience in Armenia and new structural concept for an existing 8 - story reinforced concrete hospital building to be retrofitted by base isolation. Study of Civil Engineering and Architecture (SCEA), Vol.3: pp. 78 - 92.

[10] Melkumyan M. (2006). Armenia is the one of the world leaders in development and application of base isolation technologies. "MENSHIN" Journal of the Japan Society of Seismic Isolation, No. 54: pp. 38 - 41.

[11] Melkumyan M. (2014). Structural concept and analysis of the 15 - story base isolated apartment building “Avan". International Journal of Engineering Research and Management (IJERM), Vol.1, Issue 7: pp.157 161.

[12] Melkumyan M. (2014). Structural concept and analysis of the 17 - story base isolated apartment building "Sevak". International Journal of Engineering and Applied Sciences (IJEAS), Vol.1, Issue 3: pp.13 - 17.

Citation: Mikayel Melkumyan, “Base Isolated 4-Story Hospital Building “Vanadzor” - Part 2 - Details on Construction of this Unique Building”, International Journal of Constructive Research in Civil Engineering, 6(4), pp. 01-09 DOI: https:// doi.org/10.20431/2454-8693.0604001.

Copyright: (C) 2020 Authors, this is an open-access article distributed under the terms of the Creative Commons Attribution License, which permits unrestricted use, distribution, and reproduction in any medium, provided the original author and source are credited. 